\title{
Relatos sobre memoria, olvido y la Comisión de la Verdad
}

\author{
Narrations on Memory, Forgetfulness and the \\ "Commission for Truth"
}

\section{Christian Arteaga}

Mag. En Estudios de la Cultura.

Profesor de Facso.

\section{Resumen}

Email: carteaga12@yahoo.es Fecha de recepción: Agosto de 2014 Fecha de aceptación: febrero de 2015

Este artículo realiza una lectura sobre de las nociones como memoria y olvido, a partir del trabajo que realizó de la Comisión de la Verdad desde 2007. Busca entonces esclarecer a partir de ciertos relatos a exguerrilleros del movimiento Alfaro Vive Carajo, las disputas y usos de la memoria, en el momento mismo que el autor era investigador principal de dicha Comisión; y a la vez colegir cómo cierto tipo de memoria fue emergiendo en dichas narraciones como nuevos efectos de recordación que interpelan a la presencia, la carencia y la muerte, alejándose de los sentidos patrimoniales de la memoria oficial, y por ende, del olvido, también oficial.

Palabras clave: Memoria, olvido, narración, testimonio e historia.

\section{Abstract}

This article makes a critical analysis of the notions of memory and forgetfulness on the work produced by the "Comision de la Verdad" ["Commission for Truth" in Ecuador] since 2007. This analysis seeks to clarify disputes and alternative uses of memory based on conversations with ex-guerrilla from Alfaro Vive Carajo*, collected when the author was head researcher of the said Commission. In the article, the author seeks as well to deduce how some sort of memory emerged from said narrations as new consequences of the remembrance: memories that challenge presence, limitations and death. This is a certain kind of memory which establishes a distance between itself and the official-patrimonial perception which builds the official memory; therefore it also keeps distance with forgetfulness, which is set officially as well.

[ ${ }^{*}$ Note by the translator: Alfaro Vive Carajo was a clandestine left-wing group in Ecuador, founded in 1983 and named after popular government leader and general Eloy Alfaro.]

Key Words: Memory, forgetfulness, narration, testimony, history. 
...y también la paradoja más profunda de la memoria:

el pasado es 'contemporáneo' del presente que fue.

Gilles Deleuze

\section{A modo de Introducción}

1 1 presente artículo diseña una explicación sobre el trabajo de la memoria, misma que en algunas ocasiones se concibe un significante vacío, llenado por un particular concreto y asumido como interés general por un grupo determinado; mientras que otras suponen una cartografía oficial sobre qué, cómo y cuándo recordar. En ese sentido, se intentaría problematizar e intentar temporalmente resolver las siguientes cuestiones: ¿son la memoria y el olvido, un asunto de evocación sectorial y de grupos a los cuales se los había relegado del espacio histórico en un periodo concreto? O por el contrario ¿memoria y olvido son parte del clivaje Estado-estructura donde el segundo determina al primero a partir de ciertas prácticas bajo un escenario oficial de recordación?.

En dicho escenario, este documento erige un acercamiento a partir de un trabajo de campo realizado en los años 2008-2009, tiempo en el que me desempeñé como investigador principal de la Comisión de la $\operatorname{Verdad}^{1}(\mathrm{CV})$. Esos dos años me permitieron observar y ser parte de los efectos de recordación/evocación de varios ciudadanos -casi la totalidad fueron ex militantes del movimiento guerrillero Alfaro Vive Carajo (AVC)- los cuales habían sido sometidos a encierros, torturas físicas y sicológicas,

\footnotetext{
${ }^{1}$ La Comisión de la Verdad fue creada mediante Decreto Ejecutivo el 3 de mayo de 2007 para investigar los crímenes de Estado ocurridos entre 1984 y 1988, así como otros periodos.
}

36 - Junio $2015 \bullet N^{o} 16$ encarcelamiento e incluso desaparición temporal en el periodo de los años 80 , pero con especial énfasis en la presidencia de León Febres cordero (1984-1988). De esa manera, el dispositivo de memoria que activaban los presos políticos en el momento de rendir los testimonios a la CV no era exclusivamente para la denuncia, sino para generar otro de tipo de historia. Es decir:

\footnotetext{
"En una época dada, el cruce de estos diferentes soportes (lingüísticos, conceptuales, afectivos) gobierna la forma de pensar y de sentir que troquelan las configuraciones intelectuales específicas (por ejemplo, los límites entre lo posible y lo imposible o sobre las fronteras entre lo natural y sobrenatural)."2
}

A la sazón, esto contrae cierta proposición al momento de narrar dichos eventos -como parte circunstanciales de un momento histórico en la década de los años 80 y en la región latinoamericana- y es que las denuncias de militantes, obreros, guerrilleros, sobre aquel e periodo no alcanzó el nivel de veracidad y verosimilitud en el ámbito de la historia de nuestro país. Por tal razón, el acercamiento metodológico de este documento tiene un especial privilegio pues conté con el testimonio de varias de las personas que fueron parte de los hechos como militantes o familiares, conocí lugares de memoria y olvido ${ }^{3}$, además de

${ }^{2}$ Cartier, Roger. Historia intelectual e historia de las mentalidades. Trayectorias y preguntas. En El mundo como representación. Estudios sobre historia cultural. Gedisa. España. 2005, pág.20

${ }^{3}$ Adjudico de esa manera a dichos sitios pues represen- 
mantener largas conversaciones, algunas durante días enteros con algunos/as de los militantes de AVC, mismas que me permitieron distinguir dos momentos: el primero relacionado al hecho concreto al cual se referían (bien podía ser su detención y tortura, o algún operativo importante contra las fuerzas del orden) y el segundo instante, tal vez el más valorativo y que años después he tomado en cuenta, son las nuevas memorias que iban a apareciendo, ya que: "(...) los mecanismos por los cuales unos mecanismos fundamentales de pensamiento se convierten dentro de un grupo concreto de agentes sociales, en esquemas interiorizados inconscientemente, estructurando todos los pensamientos a acciones particulares". (Cartier; 2005: 22)

Por ese motivo, presento dos subacápites que permiten ir sosteniendo las posibles respuestas a las preguntas enunciadas como parte de la construcción política y pública de la memoria y el olvido. Por lo que escogí titular estas dos viñetas como disputa/evocación y olvido/tensión, pues consienten reflexionar sobre la memoria y el olvido como parte de una construcción

tan espacios físicos en los que el poder oficial enclaustró a prisioneros políticos, así como sirvieron de headquaters clandestinos de miembros de la policía y fuerzas armadas para vigilar, detener y torturar a militantes de izquierda, guerrilleros, estudiantes, campesinos, cristiano de base, etc. De los sitios de olvido y memoria que se logró identificar están tres casas clandestinas de miembros de las fuerzas represivas de aquella época: la una, cerca de la Universidad Central del Ecuador, exactamente en la Avenida Universitaria; la otra en el céntrico barrio de San Juan y la tercera, detrás del Hotel Quito, en la avenida De los Conquistadores, tristemente conocida como la Casa de Irene, debido al título de una canción interpretada por el cantante argentino Leonardo Favio, lugar que servía de eje coordinador entre la policía y fuerzas armadas para la lucha antisubversiva, la misma que visitamos con Fidel Jaramillo, compañero de la CV -director actual de la Comisión de la verdad en la Fiscalía General del Estado desde donde se está motivando la judicialización de los casos donde en los que se violaron los derechos humanos- donde observamos que fuera de estar deshabitada por mucho tiempo, se habían hecho de los dormitorios, celdas y lugares de tortura, a más de construir espacios reducidos para poder incomunicar a una persona.. estructural que tiene a veces ciertos grados de ambigüedad y en otros momentos, de paradoja.

\section{Disputa /evocación}

En este instante puntualizo cierto contexto que puede ayudar a mirar el momento de la construcción de una memoria regional. La década de los años 80 fue calificada por la Teoría del Desarrollo como la década perdida, debido al inicio de la crisis económica, expuesta en 1982 por la crisis de la deuda externa, de la cual, México fue el primer país en declarar su moratoria. No obstante, a nivel de la movilización social se caracterizó por la importante actoría de movimientos sociales armados o grupos guerrilleros y las dictaduras centroamericanas.

El triunfo del sandinismo en 1979 posibilitó nuevamente a reafirmar -no nos olvidemos que la afirmación fue la victoria de la Revolución cubana en 1959- que la lucha armada era el camino hacia la caída de las dictaduras y la toma del poder, pues ponía fin a más de cincuenta años de dictadura de la familia Somoza y el apoyo inveterado de los Estados Unidos de Norteamérica. Cercano a dicho país, el pueblo salvadoreño agrupado en el Frente Farabundo Martí para la Liberación Nacional (FMLN) estaba en un lucha permanente contra la dictadura de ese país; en Guatemala, la Unidad Revolucionaria Nacional Guatemalteca (URNG) también en armas frente a una combinación de arremetida represiva y aniquilamiento cultural a las poblaciones indígenas por parte del Ejército al mando del general Efraín Rios Montt; en Honduras la guerrilla del Movimiento Popular de Liberación "Cinchonero" (MPL-C) eran parte de toda esta oleada revolucionaria mesoamericana que no pasó desapercibida en el callejón andino. Así, en Colombia guerrillas como el Movimiento 19 de abril (M-19) era, por opción uno de 
los sectores no tradicionales en la lucha armada (es decir, se separan de la estrategia de guerra popular prolongada (GPP) vinculada al frente campesino y su base de acciones en el campo y la selva) pues amplificaba los escenarios a la combinación de lucha rural y urbana con acciones espectaculares y de propaganda armada; los movimientos de la región andina no estaban al margen de dicho derrotero, así se encuentran experiencias similares en Bolivia con el Ejército Guerrillero Tupak Katari; en Perú, Sendero Luminoso y el Movimiento Revolucionario Tupac Amaru y en nuestro país, Alfaro Vive Carajo, Montoneras $\mathrm{Pa}$ tria Libre y un tercer grupo sin nombre se sumaron a dicho derrotero.

Una de las singularidades que pueden expresarse es que, por ejemplo, en el Ecuador, la lucha armada en la década del 80 no reivindica las consignas abiertamente socialistas y marxistas, sino que introduce el concepto -tan desdeñado en ese tiempo por los sectores de la izquierda marxista leninista ecuatoriana- de la democracia y los referente culturales de la historia nacional, como es el caso de Eloy Alfaro Delgado. De igual forma, la transición de la dictadura a la democracia en 1978 significó una negociación de las elites y sectores militares permitiendo cierto robustecimiento de los partidos políticos y del régimen institucional democrático en el país. Precisamente, las fuerzas políticas de la Sierra y de la Costa, delinearon tácitamente un pacto de gobernabilidad para el futuro, lo que no contaban era que en dicho pacto apareciera cierto outsider -promovido por partidos de corte populista como fue Concentración de Fuerzas Populares (CFP)-, como fue Jaime Roldós Aguilera.

De ese modo, la oposición al gobierno de Roldós -desde del inicio- estuvo claramente vinculada a los sectores industriales y oligárquicos de la costa. Estas acciones permitieron ir construyendo un perfil de opositor vinculado a un carácter fuerte y autoritario como forma de negociación política parlamentaria y extraparlamentaria. De esta forma, se catapultó la figura de un caudillo provincial como fue León Febres cordero, vinculado con sectores dominantes de la sierra y de la costa ecuatoriana.

Con esta mínima descripción del momento latinoamericano y ecuatoriano, se pueden puntualizar una serie de cuestiones alrededor de la experiencia ecuatoriana que, definitoriamente, marcó aquella década. En ese sentido, retraer esa década en una lanza de memoria, es complejo, por varias razones:

1.- Porque los eventos y acciones sucedidos en dicho momento jugaron con expresos niveles de ocultamiento (prensa, por ejemplo) o desinterés (la historia oficial) por considerarlos como efectos traumáticos en el desarrollo del Estado-nación ecuatoriano.

2.- Porque bajo un "utillaje" del gobierno actual, supone que las figuras históricas, en especial la de Eloy Alfaro, configura un halo de superhéroe o semidios limado de cualquier estrago o paradoja histórica. Lo que de algún modo, a los militantes de AVC, los borra -paradójicamente- de los renglones de la historia contemporánea, situándolos en algunos caso, como pequeños subsidiarios de la lucha de los años $80 \mathrm{y}$,

3.- Porque las narrativas vindicadas después de más 25 años de recuerdo suponen un acercamiento no tradicional, ni bajo el ámbito de una legitimidad otorgada por un discurso político de gobierno o de instituciones como son los ministerios. Sino por el contrario, nuevos sentidos de evocación que son traídos al presente y que se distancian de tonos y todos deferentes con los relatos héroes/villanos, bueno/malo, y se los 
construye a partir de evocaciones más terrenales y anecdóticas.

Siguiendo a Elizabeth Jelin, el asunto no queda zanjado y la disputa no sólo es frente a la historia oficial y las narrativas estatales, sino al interior mismo de las memorias y es que:

Para los defensores de los derechos humanos, el "Nunca más" involucra tanto un esclarecimiento completo de lo acontecido bajo las dictaduras como el correspondiente castigo a los responsables de las violaciones de derechos. Otros observadores y actores, preocupados más que nada por la estabilidad de las instituciones democráticas, están menos dispuestos a reabrir las experiencias dolorosas de la represión autoritaria y ponen el énfasis en la necesidad de abocarse a la construcción de un futuro antes que a volver a visitar el pasado. Desde esta postura, se promueven políticas de olvido o de "reconciliación". Finalmente, hay quienes están dispuestos a visitar el pasado para aplaudir y glorificar el "orden y progreso" de las dictaduras".

Entonces, la memoria como disputa genera otras maneras de narrar el pasado: la memoria del presente y del futuro. Esa fue una de las condiciones metodológicas de la $\mathrm{CV}$, pues se propuso desde un inicio recuperar esas memorias ocultas, en un momento, por decisiones personales o sociales para traerlas a la historia contemporánea, motivado también por la participación de Rosa Mireya Cárdenas ${ }^{5}$, Clara Merino ${ }^{6}$ y

4 Jelin, Elizabeth. Exclusión, memorias y luchas políticas. En Estudios latinoamericanos sobre cultura y transformaciones sociales en tiempos de globalización. CLACSO. Argentina. 2001, pag,99

${ }^{5}$ Militante fundadora de AVC y compañera de Fausto Basantes Borja, número dos del movimiento asesinado a tiros por las fuerzas policiales, el 4 de enero de 1986, en una calle del norte de Quito. Cárdenas es parte del Comité Ecuatoriano Contra la Impunidad (CENIMPU) que se había formado para denunciar y buscar justicias por los crímenes de Estado cometidos en la presidencia de Febres Cordero

${ }^{6}$ Hermana del dirigente de AVC, Ricardo Merino, asesi-
Francisco Acosta Coloma ${ }^{7}$ quienes hicieron parte del Comité de Soporte de la CV. Lo que significó edificar algunas cuestiones bastante suigeneris en este tipo de informe como: las propias víctimas sean las constructoras de su voz que por decisiones individuales o colectivas permanecieron por muchos años en silencio, y segundo, una de las más ininteligibles, era evitar caer en uno de los dispositivos tan graves como el propio olvido: la revictimización de la víctima, presentándola como alguien carente de decisión o voz propia, que vive al margen de sus acciones y soportando la culpa y mancha de su pasado, pues: "Así resulta el inventario de las culpas, dentro del régimen de la impureza, tiene más conexión en el ámbito delos acontecimientos del mundo y una reducción proporcional en el ámbito de las intenciones del agente" (Ricoeur; 1982:190)

En tal plexo, ¿Qué implicó la disputa con la historia oficial pasada y actual generada desde la CV? Involucró conferir bajo mecanismos orales de recordación de cada una de los víctimas, la posibilidad de amplificar su identidad, no únicamente bajo el ideal de guerrillero puro y duro, cubierto con el manto del deber ser que se expresaba en figuras de combatientes de la talla de Carlos Fonseca, Bautista van Schouwen, Miguel Enríquez, Paco Urondo, Frank País, Arturo Jarrín y muchos más, capaces de soportar todo el dolor de la muerte, toda la brutalidad de la tortura, lo espurio del confinamiento en una celda y salir incólumes físicamente o en el testimonio de su vida.

nado en junio de 1986 en una casa de seguridad en la ciudad de Cuenca. Clara Merino es activista feminista y vinculada a organizaciones de derechos humanos.

${ }^{7}$ Hermano del militante de AVC, Juan Carlos Acosta, herido de bala, torturado y asesinado en Guayaquil en el mes de agosto de 1985 por parte de miembros policiales, en e contexto de la retención del banquero Nahím Isaías Barquet 
Entonces, aquellas micronarraciones de las personas a quien pude recoger su testimonio para el informe final de la $\mathrm{CV}$, se convertían en microdisputas por partida doble: una al sentido oficial de la historia y otra, a los propios testigos y participantes de aquellos momentos que, es muy seguro, que no repararon en los detalles de las memorias que hoy se están peleando. $Y$ afirmo que se están disputando porque, según parece, aquellas conversaciones fueron y son las formas de resolver los traumas y crisis personales a partir del lenguaje, pues al narrarlas se resuelve la historia personal:

\begin{abstract}
Para quien atravesó todas las secciones de configuración y reconfiguración narrativa, desde la constitución de la identidad personal hasta de las identidades comunitarias que estructuran nuestros vínculos de pertenencia, el peligro principal, al término del recorrido, está en el manejo de la historia autorizada, impuesta, celebrada, conmemorada -de la historia oficial- ${ }^{8}$
\end{abstract}

Si uno revisa atentamente los testimonios aparecidos en los tomos del informe final de la CV, puede distinguir ciertas aseveraciones sobre la historia de cada uno de los militantes de AVC que vivió la tortura. No obstante, como en todo documento histórico, algo quedó fuera. Ese quedar fuera por ejemplo, fue las conversaciones cuando recogía los testimonios, caso concreto a Juan $\mathrm{Cuvi}^{9}$, este me sabía expresar que tan brutales habían sido las torturas por miembros de la Policía Nacional, que en un momento dado lo enviaron a Fuerzas Armadas, en ese lapso, un médico de dicha institución le había drenado la herida

\footnotetext{
${ }^{8}$ Ricoeur, Paul. La memoria, la historia, el olvido. Fondo de Cultura Económica. Argentina. 2000, pág, 572

${ }^{9}$ Miembro del Comando Central de AVC, detenido en agosto de 1985 a raíz de la retención del banquero y en ese entonces, hombre más rico del país, Nahím Isaías Barquet.
}

e inyectado penicilina para curar su rodilla infectada que le habían generado los golpes a cargo de la policía. Supo indicar que ahí su cuerpo mínimamente se repuso de tanta bestialidad (recordemos que Cuvi pasó casi un mes detenido y torturado todos los días sin descanso) que incluso habían dañado su pierna.

En otro relato, se rescata datos de la fundación del movimiento AVC, detalles sobre el momento mismo de compromiso para emprender la lucha, narrado por Patricio Baquerizo $^{10}$. Este afirmó que horas después final del congreso de fundación, un 14 de febrero de 1983, los habían distribuido en casas de seguridad y en la noche había arribado un hombre pequeño y delgado, a conversar jocosamente sin identificarse -pues todos en el encuentro habían estado compartimentados por seguridad (una capucha roja que solo dejaba ver los ojos)- y haciendo bromas a los que estaban en dicha casa, aduciendo que no se percatarían su identidad, siendo Arturo Jarrín, número uno de AVC, por lo que otro militante le había preguntado a Baquerizo, si sabía con quién estaba conversando, a lo que este expresó con cierto guiño de complicidad, que cómo no se iba a dar cuenta quien era, la altura y la voz, indicaba que era quien había sido nombrado comandante y había presidido esa reunión.

Esta línea que principió la $\mathrm{CV}$, sin expresarlo de manera estrictamente teórica, fue una de las experiencias más interesantes para construir y disputar las formas de recordación. Pues, por primera vez en nuestro país, un grupo de "delincuentes y saltabancos" como los había denominado la prensa y un Ministro de Defensa, podían

\footnotetext{
${ }^{10}$ Miembro fundador de AVC, detenido en 1984 junto con Arturo Jarrín y puesto en libertad en abril de 1985. Nuevamente detenido a finales de agosto de 1985 por la retención de Nahím Isaías Barquet.
} 
restaurar su pasado, reconstruir con nuevos recuerdos el presente, en suma, podían narrar la Mnemosyne -musa de la memoria- y repensar la muerte.

Baquerizo y Cuvi, incorporan en sus relatos el campo de lo indecible, que en este caso, es la muerte. Los dos estuvieron muy cercana a ella, en el caso de Baquerizo, este me describía mientras tomábamos algún refresco y fumábamos varias cajetillas de cigarrillos en un café del centro de Guayaquil, que en la situación de su segunda detención y tortura, él se miró fuera de su cuerpo mientras escuchaba levemente que un agente de la policía decía a su torturador que se detenga, que se está yendo (Baquerizo se estaba muriendo en plena la tortura) y, después de aquello, se había orinado debido a los choques de electricidad a la que fue sometido. Desde la mnemosyne, la muerte no es vista como la ausencia/presencia, sino como una construcción social que se erige en el yo, pero es un yo no mirado en la diferencia sino en la mismidad. Debido a eso se justificaron las violaciones a los derechos humanos, pues ellos -Cuvi y Baquerizo- representaban la diferencia, por lo que resultaban peligrosos.

Por ello, en tales testimonios, sin decirlo, los dos ex militantes, asumen a la memoria como un indecible que es atraído por la ausencia de alguien, o por la memoria de ese alguien. Es decir, mientras narran asumen al lenguaje como dispositivo de recuerdo, pues la memoria en este caso es lenguaje, es a la vez una metáfora de la muerte. Cuvi demostró una zanja que no cierra, y es la muerte de Juan Carlos Acosta, por ese motivo en el diálogo que mantuvimos en 2009, era recurrente nombrarlo como "Juanca", de ese modo intentaría disputar la muerte para traer el recuerdo de Acosta de manera positiva, mediante el otro que vive en él, ese otro es Acosta. Porque su huella o su traza está en el "no- sotros" de AVC, y donde se vive es en la memoria de aquel que se ha ido.

En ese encuentro, pude observar que en Cuvi, la memoria es una metáfora que nos dice que hay que repensarla desde su futuro, a diferencia de Baquerizo donde la memoria se la acarrea en el presente. Justamente, cuando el segundo narró momento de la retención de Isaías, recordó en esa charla cosas como cuando Isaías estaba guarecido en una casa, este pedía jugar ajedrez y leer la biblia con Fausto Basantes, que había ido a Guayaquil para apoyar en dicho operativo ${ }^{11}$.

En un proceso de evocación/disputa, la memoria es hacer hablar a lo indecible. Empero, existen ciertas preocupaciones relacionadas con la memoria que asaltan a este artículo. La primera es la de género literario; pues, lo que se conoce como autobiografías, elevada por sobre una literatura da como resultado una "figura de lectura" interiorizando toda una estructura de especulación sobre lo que se es y lo que se ha hecho. El segundo problema con el cuál se tiene que lidiar es la totalización, entendiendo a esto como la incapacidad de amnesia del yo, por tanto, se inscribe dentro de las obligaciones cognitivas de lo que el momento actual conmina a recordar. Y una preocupación final, es la performativa que no es más que hacer lo que se dice (en la tradición de la filosofía del lenguaje no desde Wittgestein sino desde John Austin), y en este caso tales preocupaciones relacionadas con la memoria, son en sí epitafios desde donde se dice lo que se hace, y se hace lo que se dice, como un leit motiv que ordena a los ex militantes de AVC a estruc-

\footnotetext{
${ }^{11}$ Ejemplo de lo referido en líneas anteriores lo podemos comprender macronarrativamente en la imagen del líder indígena, Tupac Katari, mismo que fue descuartizado en el siglo $\mathrm{XVII}$, recuperado y pensado en el presente y futuro, de una historia que ya pasó, por tanto, no es ya el pasado lo que determina la vida.
} 
FACSO-UCE

turar la memoria en términos apoteósicos y épicos.

Ahora bien, la memoria como evocación impone un indecible, y ese indecible es la muerte. Es tal vez, una de las formas más fuertes desde dónde pensar la muerte. $Y$ ésta entendida como una memoria interiorizante, pues no es limitante de la vida, de ahí es que podemos vincular el poema Masa de César Vallejo, donde el cadáver sigue muriendo mientras no está en la memoria de todos, porque permanece en su afirmación negativa. Y el cadáver se levanta y camina cuando todos lo evocan desde la muerte.

Por eso es que los dispositivos de memoria se activan cuando los testimonios de ex militantes de AVC se referían a los compañeros caídos y asesinados, verbigracia de esto lo pude colegir en una conversación con Mireya Cárdenas cuando me supo decir que el momento mismo del asesinato a Fausto Basantes, fue cuando tomó en serio la idea de la muerte, pues nunca había pensado que aquello podía ocurrir y por ende, se sentía culpable de haber quedado viva en esos momentos. Entonces, como el cadáver del poema de Vallejo, la muerte existe en el "nosotros" como memoria. Es algo que no está dicho. Y se lo hace hablar desde la palabra. No obstante, en esa plática apareció algo nuevo en la evocación de Cárdenas y era el duelo como característica de lo imposible, pues evocaba la muerte de $\mathrm{Ba}$ santes desde sí mismo. Empero, al mismo momento rompe esta idea de duelo imposible, planteando al duelo que sale de sí para intentar ser afirmativo.

Luego, el duelo -como parte de la memoria- viene por lo que nos ocurre y no antes de esa terrible experiencia: la economía de la muerte. La muerte existe en medida de la finitud de la memoria y la relación con el otro ausente, como deja ver Cárdenas y Cuvi. De ahí que el olvido sea otra forma de la muerte. Es decir, estos testimonios que evocan la memoria y disputan la muerte, se convierten en una suerte de metonimia: estas partes hacen hablar al todo que está en y por el "nosotros" de AVC. Es decir, para cerrar esta viñeta, muerte y memoria, son la reafirmación del otro en la otredad. La muerte les llega desde ese otro, desde ese indecible. Podría ser el silencio.

\section{Olvido/tensión}

Este punto quiero enfatizar en una cuestión: cómo el olvido estructural adopta la tensión ante las memorias que cimientan fiabilidad histórica. La CV partió de esa idea, por tal razón, todo testimonio recogido se entendía que tenía grados de fiabilidad que debía ser contrastado con fuentes y los bagajes del investigador. En mi caso, partí expresamente del testimonio para verificarlo con bibliografía y hemerografía de la fecha, jamás sugiriendo cierta inconsistencia o no veracidad del testimoniante, sino para derivarlo y observarlo en el contexto que se había desarrollado. Ciertamente, dos relatos sirven para ilustrar lo expuesto, el primero de Romel Jumbo ${ }^{12}$ quien al ser arrestado estuvo a punto de morir por una ráfaga de metralla realizada por un miembro de Fuerzas Armadas. Este refería que posterior a los disparos observaba a cómo su sangre salía imparable por el pecho, pero luego se contempló en una especie de sensación ingrávida dentro de un túnel oscuro con una luz al final, en el que logró divisar a un familiar suyo que ha-

\footnotetext{
12 Militante de AVC detenido en un operativo de recuperación bancaria en el Valle de los Chillos (suroriente de Quito) en abril de 1986; herido con proyectiles de metralla, fue torturado en el Hospital Eugenio Espejo por miembros de la Policía Nacional acompañados de un galeno policial; posteriormente trasladado a una casa clandestina de la policía y martirizado nuevamente antes de ser trasladado al expenal García Moreno.
} 
bía fallecido hace algún tiempo; inmediatamente a esta imagen escuchó el sonido parecido a una aspiradora, misma que lo engullía y lo devolvía a este mundo.

Esta narración, independientemente de su tono místico, reconstruye la estructura de la memoria que supone los presentes pasados como un presente con la idea de promesa. Dicha promesa es recordar la muerte y saberse vivo. Pero también, aquella promesa es la memoria, no únicamente en la apariencia de una palabra, sino que su palabra preserva una relación esencial con el tiempo extra terreno. De ese modo, la memoria pone en angustia al olvido, pues reincorpora otras estrategias narrativas que deja por fuera el materialismo del militante óptimo y epigonal. Pues, en Jumbo:

\begin{abstract}
"Reencontramos así, en el camino de la reconquista del dominio de su capacidad de narrar que realizan los agente sociales, todos los obstáculos vinculados al desmoronamiento de las formas de ayuda que la memoria de cada uno puede encontrar en la de los otros en cuanto capaces de autorizar, de ayudar a crear relato a la vez de modo inteligible, aceptable y responsable". ${ }^{13}$
\end{abstract}

En aquel momento la memoria encuentra su huella en el tiempo, y este último como la sucesión de presentes continuos, conectándose mediante el diálogo con la idea de futuro, como un presente que debe venir, por lo que es a la vez traer aquel indecible (olvido/muerte) al presente. No obstante, en este relato también se construye un obstáculo que es la necesidad de recordar lo que se olvidó en aquellos tiempos, y después varios años regresa con cierto grado de nitidez, pues:

Cuando un individuo emprende por su propia cuenta un trabajo de recuperación del pasado se agrega un segundo proceso de

\footnotetext{
${ }^{13}$ Ricoeur, Paul. La memoria, la historia, el olvido. Fondo de Cultura Económica. Argentina. 2000, pág, 573

selección, consciente y voluntario: de todos los rastros dejados por el pasado, escogeremos retener y consignar sólo unos determinados por juzgarlos por alguna razón, dignos de ser perpetuados. A este trabajo de selección necesariamente le sigue otro, de disposición y por lo tanto de jerarquización de los hechos: algunos serán puestos en relieve, otros, expulsados a la periferia." ${ }^{14}$

Es decir, Jumbo, de algún modo sabe que ese detalle se vuelve digno de ser narrado, pues el pasado es ausencia, y en su efecto más radical, se vuelve fantasmagórico. Se evoca una presencia donde la casi muerte ha calado, es decir, desde la ausencia de la vida, y al igual que en la novela Aura de Carlos Fuentes, los protagonistas principales son, a contrapelo, los fantasmas de un futuro en el que su evocación es enunciada desde el pasado.

Habría algo que me permito añadir, y es que para algunos militantes de AVC -después de escuchar su narración sobre la muerte- se puede colegir que está es pensada solo y desde la vida. Por ello, la posibilidad que constituyó la $\mathrm{CV}$, radica en otro punto de tensión y fue la de generar en la memoria, ciertos de rasgos que puedan explicar su analogía entre mnemosyne y leteo (río que llega al erebo o infierno, y que si uno se baña en sus aguas pierde por completo la memoria), es decir, un tipo de olvido que piensa y una memoria que olvida.

Con relación a esto que he enunciado traigo a colación el relato de Jimmy Herre$\mathrm{ra}^{15}$ quien manifestó sobre las vicisitudes del operativo de recuperación bancaria en relación al día de su detención, que van

\footnotetext{
${ }^{14}$ Todorov, Zvetan. Los dilemas de la memoria. Disponi-
en: http://www.jcortazar.udg.mx/sites/default/files/TODO-

${ }^{14}$ Todorov, Zvetan. Los dilemas de la memoria. Disponi-
ble en: http://www.jcortazar.udg.mx/sites/default/files/TODOROV.pdf. Acceso: 24/07/2014.

${ }^{15}$ Militante de AVC, detenido en abril del 1986 en un operativo de recuperación bancaria en el Valle de los Chillos, torturado en el Servicio de Investigación Criminal (SIC) y después encarcelado en el expenal García Moreno.
} 
desde el no poder conseguir el óptimo vehículo para su acción, hasta un evento no planificado y de índole nacional que definió y echó abajo la actividad emprendida por militantes de AVC, -la toma de dos instituciones bancarias al mismo momentoque fueron las primeras escaramuzas del general de la Fuerza Aérea Frank Vargas Pazzos (que serían los hechos que desembocarían en el evento conocido como "El Taurazo", en 1987, donde militares insurrectos retuvieron al presidente León Febres Cordero en la Base Aérea de Taura en la provincia del Guayas) y el sobrevuelo de aviones que este desplegó por encima del Palacio de Carondelet y posteriormente un tiroteo intenso en la Base Aérea del norte de la capital.

Estos hechos determinaron que el operativo de la toma de los bancos y el escape no sea efectivo. Consecutivamente, el relato de Herrera retomó cuestiones que podrían pasar por una simple atribución, pero que en el horizonte de este artículo se incorpora a un tipo de memoria determinada por el olvido, pues cuando Herrera fue detenido, el segundo paso fue encapucharlo, el tercer paso, trasladarlo al SIC y finalmente, torturarlo. Posterior a esta, en un momento de respiro, algunos familiares conocieron de su arresto trasladándose a dicho centro policial, ahí Herrera recordó en un tono, no hierático sino de trabajo de la memoria como un tío suyo, le hizo llegar comida, específicamente, un pollo asado, el cual quedó entero por la incapacidad de comer debido a los golpes infligidos por los agentes.

Este enunciado comprueban algo, y es que lejos del relato de víctima que usualmente pueden asumir las personas que han pasado por tipos de abyecciones como la tortura, el encierro, la incomunicación, etc, Herrera como Jumbo, gracias a la tensión del olvido evaden dicha concepción, y más bien lo desplazan al ámbito de un nuevo recuerdo que en la conversación mantenida, dichas "banalidades" reconocen distinguir los detalles que fueron constituyendo esa tensión, que seguramente, Herrera y Jumbo no lo consideraron digna de relatarse. En ese plano:

\begin{abstract}
Recordar las páginas del pasado en las que nuestro grupo no es ni héroe puro ni víctima pura sería, para los autores de esos relatos históricos, un acto de valor moral superior. No hay beneficio moral posible para el sujeto si su evocación del pasado consiste en instalarse en un buen rol; si por el contrario, esta evocación le hace tomar conciencia de las debilidades y errores de su grupo se genera ese beneficio ${ }^{16}$.
\end{abstract}

La cita anterior demostraría lo expresado por Jumbo y Herrera, pues parten del principio de desacralizar una memoria épica y generar una lucha contra un olvido obligado, ya que en los dos existió esa necesidad de tensionar al olvido mediante la memoria, pero sobre todo, entender que al recordar se imprime nuevamente el sello identitario. En estos relatos está presente la impronta de AVC, y no únicamente por su capacidad operativa, su resistencia a las torturas o la martirización de sus líderes, o su conclusión de guerrilla juvenil, sino por esa identidad de lo sencillo, la experiencia mística de estar en la muerte (en el caso de Jumbo) y las vicisitudes (el vehículo y el pollo asado de Herrera) suponen esa otra memoria.

Estos acercamientos traen a colación aquella distinción entre la Gedächtnis como memoria que piensa y la Erinnerung como memoria interiorizante. Y estas dos categorías se enlazan en lo que se conoce como el nombre. El nombre es al cual apelamos para traerlo desde la muerte, es decir, el

16 Todorov, Zvetan. Los dilemas de la memoria. Disponible en: http://www.jcortazar.udg.mx/sites/ default/files/TODOROV.pdf. Acceso: 24/07/2014 
propio Alfaro, Basantes o Jarrín. En lo tocante a Romel Jumbo, la Erinnerung expone aquellas panoplias que no lo dejan redimirse cuando casi es asesinado; con respecto a Jimmy Herrera, la Gedächtnis detona su narrativa, una memoria que piensa el detalle no dicho ni trascendente.

Quisiera en este punto reflexionar sobre algo. Los testimonios expresados en este subacápite, nunca clausuraron la posibilidad de reafirmarse identitariamente con un grupo o con un nombre. En este asunto, el nombre es la memoria que expresa la carencia; y la carencia más absoluta es la muerte. Es decir, los dos militantes evocan la carencia como memoria, pues en tal situación, el pasado no es lo que existe precisamente, sino la memoria.

Sin embargo, en el enlace de mnemosyne y leteo está imbricada la verdad o aletheia, que podríamos entender como la diferencia entre ambas. Y lo interesante de esta pretensión de verdad o relato fiable, es que posee una relación consigo mismo únicamente a través del otro, Jumbo da la pauta a Herrera, y en un relato fractal esto genera otros fragmentos. El esfuerzo por conocer las memorias y los olvidos ocurre desde el límite, desde los bordes, pues las totalidades de una sola memoria y un único olvido dejan de lado a los otros relatos, por ende, las otras memorias. Sólo en lo no dicho se puede conocer a la memoria, es decir, en su lado nodal que es la transformación.

De esta manera, la memoria -en los dos testimonios- existe en la letra y la palabra que la constituye y su arte radica en leer en la memoria con ayuda de dos figuras de la propia memoria: "la una pretende contar historia -alegoría diacrónica- y la otra finge amnesia -la alegoría sincrónica-"(Derrida, 1989). Por lo que aquello, tensiona el olvido como una estructura y la memoria y lo aboca como una estrategia lo que los hace también evocar desde la muerte apelando a la vida. Ya que desde la muerte se habla del pasado. Por eso, aquellas memorias se entenderían como un claroscuro del pensamiento.

\section{Epilogo}

Agrupando lo tratado en las viñetas anteriores podría considerar algunas cuestiones bajo un cierto orden. Precisamente, la memoria/olvido fue parte cardinal para la comprensión sobre hechos traumáticos en un determinado período, y que esto pudo ser visualizado por el trabajo de la CV en su informe final. No sólo por la "(...) propia definición de qué es "vivir en carne propia" o ser "víctima directa" es también parte del proceso histórico de construcción social de sentido" (Jelin; 2002: 60) en función de las voces no oficiales que fueron los torturados en la década de los años 80.

Por otro lado, este documento me permitió reconstituir ciertas memorias que voluntaria o involuntariamente había desplazado para seleccionar otros sentidos y narraciones. Este esfuerzo personal por volver a constatar lo sinuoso que resulta la memoria y el olvido, es también una posibilidad de repensar aquellas evocaciones que estuvieron ahí, pero escamoteadas por mi dinámica de selección. Sobre todo al momento de hiperrecordar o metaolvidar, que sin duda, es un ejercicio permanente de disputa a las narraciones oficiales con los relatos de otra índole. En tal plexo, los testimonios de Cuvi, Baquerizo y Cárdenas esgrimen aquello: la memoria, los tipos de memoria se activan con el dispositivo del tiempo pasado y en el presente rompe con el sentido de propiedad sobre hechos históricos de gran calado. De esa manera, se quiebra aquel juicio patrimonial de memoria y olvido, en el que se recuerda lo que el poder determina y se olvida lo que las élites también lo conminan, y viceversa.

En los relatos de Jumbo y Herrera la 
dimensión de la memoria sigue siendo inquietante, pues emerge una tensión entre el peligro de concebir la memoria como parte de un conglomerado épico en tanto hecho de olvido, y por el contario, es el resultado de un trabajo a voluntad sobre aquello que estuvo por fuera de los márgenes legítimos de recordación. Estos testimonios articulan puntos para comprender el asunto de la memoria en los planos de la muerte y el lenguaje. De tal forma, tanto en estos como en los tres primeros relatos, logramos advertir cómo la muerte va siendo constitutiva del acto de rememoración, donde el olvido es tensionado por el pasado como un límite.

Es palmario que memoria y olvido van casi de la mano con la historia. Tanto el uno como el otro la influencian para que esta sitúe y legitime lo imponderable del recuerdo y lo benevolente del olvido; aun cuando adopte una serie de prácticas brutales o ciertas dinámicas ejemplares, dignas de recordación. Por lo que el poder y las élites han vaciado de esfuerzo el acto de memoria, y la han destinado a una aparente y desdeñosa inercia sobre los actos por la memoria, emplazándola en la reparación de lo impuro y lo culpable, por lo que todo acto por fuera de la línea mecánica del poder y su construcción de la historia, asi: "(...) engloba en su esfera de impureza las consecuencias de los actos y los acontecimientos impuros" (Ricoeur; 1982: 191).

Es decir, los agentes de la memoria, en este caso los militantes de AVC, fueron concebidos por la historia como impuros por desacralizar la memoria de Alfaro, único -según la oficialidad- revolucionario y gestor de la única revolución en nuestro país. Sé muy bien los límites que puede tener este documento a la hora de querer totalizar la memoria, pues parafraseando a Ricoeur (2000; 576) ver una cosa no es ver otra. Narrar un drama es olvidar otro. Asu- mo con la mayor responsabilidad dichas palabras, empero, puedo aseverar que esto es una permanente tensión sobre lo escrito hasta ahora, ya que parte de una memoria de la que fui parte y que la escribí como investigador de la CV.

Ante ello, queda entonces generar otras memorias sobre lo oficial, pues y para finalizar desearía cerrar con una cita medianamente extensa que resume lo que he reflexionado en este texto:

La historia es un esfuerzo de memoria; como narración, sin embargo, también es una expresión de poder de las élites dominantes. El poder instala en el pasado lo que a estas élites les resulta conveniente decir, en esta perspectiva da contenido al pasado. Además, estatuye la manera de contarlo (...) Como toda narración, la historia condena a la desmemoria una parte de lo acontecido: aquello que representa lo innombrable. De este modo, la historia estatuye e inventa, en función de los intereses de clase lo que fue $(. .$.$) e instala en le recuerdo el pa-$ sado. No por otra razón, a partir de este momento, la crítica aparece como un acto celebratorio de un acontecimiento siempre reiterado en el relato por la desmemoria. ${ }^{17}$

\footnotetext{
${ }^{17}$ Espinosa, Roque. Desmemoria y Olvido. La economía arrocera en la cuenca del Guayas 1900-1950. Universidad Andina Simón Bolívar y Corporación Editora Nacional. Ecuador. 2014, pág 532.
} 


\section{BibLIOGRAFÍA}

Cartier, Roger. Historia intelectual e historia de las mentalidades. Trayectorias y preguntas. En El mundo como representación. Estudios sobre historia cultural. Gedisa. España. 2005

Deleuze, Gilles. El bergsonismo. Ediciones Cátedra. España. 1996

Derrida, Jacques. Memorias para Paul De Man. Gedisa. Editorial. España. 1989

Espinosa, Roque. Desmemoria y Olvido. La economía arrocera en la cuenca del Guayas 1900-1950. Universidad Andina Simón Bolívar y Corporación Editora Nacional. Ecuador. 2014.

Jelin, Elizabeth. Exclusión, memorias y luchas políticas. En Estudios latinoamericanos sobre cultura y transformaciones sociales en tiempos de globalización. CLACSO. Argentina. 2001. Los trabajos de la memoria. Siglo veintiuno editores. España. 2002

Ricoeur, Paul. Finitud y culpabilidad. Taurus. España. 1986

2000.

, La memoria, la historia, el olvido. Fondo de Cultura Económica. Argentina.

Todorov, Zvetan. Los dilemas de la memoria. Disponible en: http://www.jcortazar.udg.mx/ sites/default/files/TODOROV.pdf. Acceso: 24/07/2014 